\title{
Novel glutamatergic drugs for the treatment of mood disorders
}

\author{
This article was published in the following Dove Press journal: \\ Neuropsychiatric Disease and Treatment \\ 8 August 2013 \\ Number of times this article has been viewed
}

\section{Kyle AB Lapidus \\ Laili Soleimani \\ James W Murrough}

Mood and Anxiety Disorders Program, Department of Psychiatry, Icahn School of Medicine at Mount Sinai, New York, NY, USA
Correspondence: James W Murrough Icahn School of Medicine at Mount Sinai, One Gustave L Levy Place, Department of Psychiatry, Box 1230, New York, NY 10029, USA

$\mathrm{Tel}+|2| 224 \mid 7574$

Email james.murrough@mssm.edu
Abstract: Mood disorders are common and debilitating, resulting in a significant public health burden. Current treatments are only partly effective and patients who have failed to respond to trials of existing antidepressant agents (eg, those who suffer from treatment-resistant depression [TRD]) require innovative therapeutics with novel mechanisms of action. Although neuroscience research has elucidated important aspects of the basic mechanisms of antidepressant action, most antidepressant drugs target monoaminergic mechanisms identified decades ago. Glutamate, the major excitatory neurotransmitter in the central nervous system, and glutamatergic dysfunction has been implicated in mood disorders. These data provide a rationale for the pursuit of glutamatergic agents as novel therapeutic agents. Here, we review preclinical and clinical investigations of glutamatergic agents in mood disorders with a focus on depression. We begin with discussion of evidence for the rapid antidepressant effects of ketamine, followed by studies of the antidepressant efficacy of the currently marketed drugs riluzole and lamotrigine. Promising novel agents currently in development, including $N$-methyl-D-aspartate (NMDA) receptor modulators, 2-amino-3-(3-hydroxy-5-methyl-isoxazol-4-yl) propanoic acid (AMPA) receptor modulators, and drugs with activity at the metabotropic glutamate (mGlu) receptors are then reviewed. Taken together, both preclinical and clinical evidence exists to support the pursuit of small molecule modulators of the glutamate system as novel therapeutic agents in mood disorders. It is hoped that by targeting neural systems outside of the monoamine system, more effective and perhaps faster acting therapeutics can be developed for patients suffering from these disabling disorders.

Keywords: glutamate, mood disorders, major depressive disorder, ketamine, NMDA, AMPA

\section{Introduction}

Mood disorders represent a tremendous worldwide public health burden. According to the World Health Organization (WHO), unipolar depressive disorders account for 65.5 million disability-adjusted life years (DALYs) lost and rank third among leading causes of global disease burden. ${ }^{1}$ Among all brain-based disorders, unipolar depressive disorders rank first; bipolar disorder (BPD) ranks fourth, accounting for 14.4 million DALYs lost. ${ }^{1}$ Compounding this large disease burden, current treatments for mood disorders remain only partially effective and are associated with a long lag time to onset of therapeutic efficacy. ${ }^{2}$ It is estimated that more than one-third of patients with major depressive disorder (MDD) suffer from treatment-resistant depression (TRD), defined as a failure to achieve antidepressant response to one or more antidepressant treatments of adequate dose and duration. ${ }^{3}$ For this group of patients in particular, 
current monoaminergic antidepressant agents are inadequate and innovative therapeutics with novel mechanisms of action are urgently needed.

Current pharmacological options for MDD include the serotonin-selective reuptake inhibitors (SSRIs), serotonin norepinephrine reuptake inhibitors (SNRIs), atypical antidepressants (eg, bupropion, mirtazapine), tricyclic antidepressants (TCAs), and monoamine oxidase inhibitors (MAOIs). Treatment options for BPD include lithium, anticonvulsants (eg, valproic acid), and antipsychotic agents. Remission (defined as resolution of symptoms) is the ultimate therapeutic goal in the treatment of mood disorders and it is associated with improved long-term outcomes and lower relapse rates. ${ }^{4}$ Patients with MDD who have failed to respond to two treatments experience significantly reduced remission rates $(10 \%-20 \%)$ following the next treatment trial and no specific treatment option appears superior to alternatives. ${ }^{5}$ Depressive symptoms and episodes represent the predominant source of disability associated with BPD and are often particularly difficult to treat., ${ }^{6,7}$ When mood disorder symptoms persist despite an optimized trial with a first-line therapeutic agent, there is no clear guidance on the next best treatment steps. The standard of care for MDD consists of a trial and error approach involving sequential monotherapy trials with antidepressant agents and augmentation or combination strategies. A similar approach represents the standard of care for BPD. Careful assessment, re-evaluation of diagnosis, a high suspicion for occult substance or general medication problems, attendance to environmental factors, and consideration of psychotherapy all constitute important aspects of the clinical management of mood disorders.

Although neuroscience research has elucidated important aspects of the basic mechanisms of antidepressant action, ${ }^{8}$ the majority of antidepressant drugs target monoaminergic mechanisms identified decades ago. After several unsuccessful attempts by the industry to develop drugs active at new molecular targets for mood disorders, several major pharmaceutical companies have recently eliminated or reduced $R \& D$ investment in neuroscience therapeutics. ${ }^{9}$ The remaining programs tend to focus on 'safe' targets rather than potentially paradigm-shifting therapies, although there exist important exceptions. There is an undeniable public health imperative to develop new therapies for TRD to address persistent mood symptoms, promote sustained remission, and improve quality of life.

Herein, we provide a narrative review of preclinical and clinical investigations of glutamatergic agents in mood disorders with a focus on depression and agents with antidepressant activity. Our literature review included searches of PubMed, NCBI, and ClinicalTrials.gov databases and the search terms, 'depression', 'major depression', 'major depressive disorder', 'mood disorder', 'bipolar disorder', 'treatment', 'antidepressant treatment', 'mood stabilizers', and 'glutamate', as well as each specific class and drug name discussed in the manuscript. We begin by reviewing the glutamate system and the evidence supporting the rapid antidepressant effects of ketamine. Subsequently, we review evidence concerning the antidepressant efficacy of the currently marketed drugs riluzole and lamotrigine. We then discuss novel agents currently in development, including $\mathrm{N}$-methyl-D-aspartate (NMDA) and 2-amino-3-(3-hydroxy5-methyl-isoxazol-4-yl) propanoic acid (AMPA) modulators and drugs with activity at the metabotropic glutamate receptors (mGluRs). We conclude with a discussion of the current state of glutamatergic antidepressant agents and future directions for therapeutic development. The scope of this review precludes detailed discussion regarding the efficacy and off-target effects of each agent and the reader is therefore referred to the relevant primary publications for additional details.

\section{Glutamatergic neurotransmission as an emerging therapeutic target in mood disorders}

Glutamate is the major excitatory neurotransmitter in the central nervous system (CNS) and plays a central role in synaptic plasticity, learning, and memory..$^{10}$ Glutamate is packaged into synaptic vesicles for calcium-dependent release, which enables binding to ionotropic and metabotropic receptors (see Figure 1). The ionotropic glutamate receptors include NMDA, AMPA, and kainate receptors. Metabotropic glutamate receptors all initiate signal transduction cascades via G-protein coupling and are divided into three groups: Group I (mGluR1 and mGluR5), Group II (mGluR2 and mGluR3), and Group III (mGluR4, mGluR6, mGluR7, mGluR8). Glutamate is not significantly degraded extracellularly and instead is transported into glia by excitatory amino acid transporters (EAATs) and is the primary mechanism by which clearance occurs. The glial cell - together with the pre-synaptic and postsynaptic neurons - make up the 'tripartite synapse' which functions to exert tight regulatory control over levels of synaptic and extra-synaptic glutamate. Excessive levels of glutamate result in the well described phenomenon for neuronal excitotoxicity. The extensive molecular machinery 


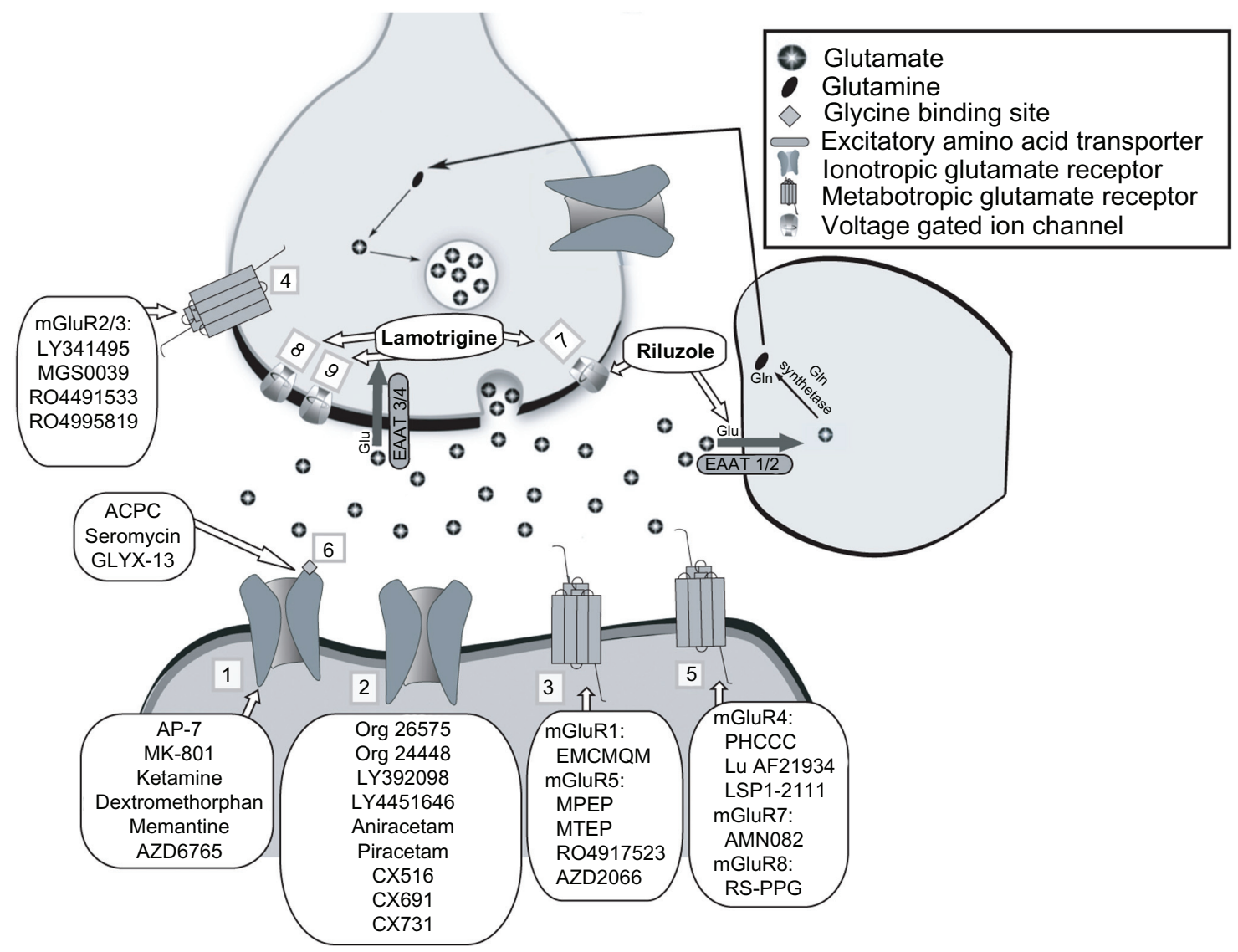

Figure I Molecular targets of glutamatergic drugs for mood disorders.

Notes: Sites of action and regulation for glutamate neurotransmission are shown, and drugs that target each specific site/mechanism are indicated. The specific locations depicted here are representative, though ionotropic and metabotropic glutamate receptors may be located on both presynaptic and postsynaptic cells. Numbers indicate the following targets: (I) NMDAR; (2) AMPAR; (3) Group I mGluR; (4) Group II mGluR; (5) Group III mGluR; (6) Glycine site of NMDAR; (7) Na+ Channel; (8) Ca ${ }^{++}$Channel; (9) K+ Channel. Abbreviations: AMPAR, 2-amino-3-(3-hydroxy-5-methyl-isoxazol-4-yl) propanoic acid receptor; EAAT, excitatory amino acid transporter; Gln, glutamine; mGluR, metabotropic glutamate receptor; NMDAR, N-methyl-D-aspartate receptor; MTEP, 3-((2-methyl-4-thiazolyl)ethynyl)pyridine; PHCCC, (-)-N-phenyl-7-(hydroxyimino) cyclopropa[b]chromen-la-carboxamide; EMCMQM, (3-ethyl-2-methyl-quinolin-6-yl)-(4-methoxy-cyclohexyl)-methanone methanesulfonate; Glu, glutamate; ACPC, I-aminocyclo-propanecarboxylic acid.

regulating glutamate signaling provides multiple targets of glutamatergic drug development (Figure 1).

Evidence from postmortem and in vivo brain imaging studies implicates amino acid neurotransmitter systems in the pathophysiology of MDD. Increased cortical glutamate levels were detected in postmortem samples from patients with bipolar and unipolar depression. ${ }^{11}$ Imaging studies with magnetic resonance spectroscopy (MRS) have demonstrated abnormalities in regional glutamate, glutamine, and GABA in patients with depression. ${ }^{12,13}$ For example, Sanacora et al reported an increase in cortical glutamate along with decreases in GABA in depression. ${ }^{13}$ These brain abnormalities are consistent with observed alterations in peripheral blood and cerebrospinal fluid glutamate levels as well as postmortem studies of glutamate receptors. ${ }^{14}$ One postmortem study demonstrated altered NMDA receptor (NMDAR) binding and used in situ hybridization to identify cortical decreases in a variety of glutamate receptor components in both BPD and MDD. ${ }^{15}$ Notably, traditional monoamine-based antidepressants have been found to regulate glutamate receptor expression and function. ${ }^{16}$ Taken together, these data implicate altered glutamate signaling in mood disorders and provide a rationale for the pursuit of glutamatergic agents as novel therapeutic agents. ${ }^{17-19}$

\section{Ketamine}

Ketamine is a non-competitive glutamate NMDAR antagonist currently approved as an anesthetic agent. Ketamine is classified as a dissociative anesthetic and produces an anesthetic state characterized by preserved pharyngeal reflexes and cardiovascular and respiratory stimulation when administered intravenously (IV) at doses of $1-3 \mathrm{mg} / \mathrm{kg} .{ }^{20}$ While IV is the typical route of administration, additional routes include intramuscular (IM), intranasal (IN), epidural, subcutaneous, transdermal, and oral. 
Table I Glutamatergic agents in depression-like animal models

\begin{tabular}{|c|c|c|c|c|}
\hline Target & Drug & Major mechanism of action & Treatment effect & $\begin{array}{l}\text { Reference } \\
\text { numbers }\end{array}$ \\
\hline \multirow[t]{2}{*}{ NDMAR } & Ketamine & Non-competitive antagonist & $\begin{array}{l}\text { Antidepressant effects in CS, TST, FST, LH, } \\
\text { and NSFT; increases in synaptic density }\end{array}$ & $30,74,120$ \\
\hline & Memantine & Non-competitive low-affinity antagonist & Antidepressant effects in FST and CS & 116,121 \\
\hline NMDAR glycine & GLYX-I3 & Partial agonist at glycine site & Antidepressant effects in FST and LH & 72 \\
\hline NMDAR GluN2B & Ro25-698I & GluN2B selective antagonist & Antidepressant effects in FST and CS & $73-76$ \\
\hline \multirow[t]{4}{*}{ AMPAR } & Aniracetam & PAM & Mixed antidepressant effects in FST & 88,89 \\
\hline & $\begin{array}{l}\text { CX516; CX691; } \\
\text { CX73I; piracetam }\end{array}$ & PAMs & $\begin{array}{l}\text { Possible anxiolytic vs antidepressant } \\
\text { effects on submissive behavior }\end{array}$ & 88 \\
\hline & LY392098 & PAM & $\begin{array}{l}\text { Antidepressant effects in FST and TST, } \\
\text { but no effect in CS }\end{array}$ & $85,87,122$ \\
\hline & LY45I646 & PAM & Mixed antidepressant effects in FST and TST & 86 \\
\hline Group I mGluR I & EMQMCM & mGluRI antagonist & Antidepressant effects in FST and TST & 97,98 \\
\hline \multirow[t]{2}{*}{ Group I mGluR5 } & GRN-529 & mGluR5 NAM & Antidepressant effects in FST & 96 \\
\hline & MPEP; MTEP & mGluR5 antagonists & Antidepressant effects in FST and TST & $92-95,98$ \\
\hline \multirow[t]{3}{*}{ Group II mGluR } & LY34I495 & $\mathrm{mGluR} 2 / 3$ antagonist & $\begin{array}{l}\text { Antidepressant effects in TST, FST, and } \\
\text { nicotine-withdrawal-related ICSS elevation }\end{array}$ & $101-104$ \\
\hline & MGS0039 & $\mathrm{mGluR} 2 / 3$ antagonist & $\begin{array}{l}\text { Antidepressant effects in LH, TST, and FST; } \\
\text { anxiolytic effects in conditioned fear }\end{array}$ & $99-101$ \\
\hline & RO449I533 & mGluR2/3 NAM & Antidepressant effects in TST and FST & 103 \\
\hline \multirow[t]{2}{*}{ Group III mGluR } & ACPT-I & mGluR group III agonist & Antidepressant effects in FST & $105,106,108$ \\
\hline & & & $\begin{array}{l}\text { No antidepressant effects in FST and TST } \\
\text { following peripheral administration }\end{array}$ & 107 \\
\hline \multirow[t]{3}{*}{ Group III mGluR4 } & Lu AF21934 & mGluR4 PAMs & No effect in FST and TST & 109,110 \\
\hline & LSPI-2III & & & \\
\hline & PHCCC & mGluR4 PAM & $\begin{array}{l}\text { No antidepressant effect in FST alone; } \\
\text { antidepressant effects in FST when given } \\
\text { with mGluR Group III antagonist, ACPT-I }\end{array}$ & 108 \\
\hline Group III mGluR7 & AMN082 & mGluR7 agonist & Antidepressant effects in FST and TST & 111 \\
\hline Group III mGluR8 & RS-PPG & mGluR8 agonist & Antidepressant effects in FST & 106 \\
\hline \multirow[t]{3}{*}{ Other } & Riluzole & $\begin{array}{l}\text { Reduces extra-synaptic glutamate } \\
\text { by inhibiting presynaptic release, } \\
\text { enhances astroglial uptake }\end{array}$ & $\begin{array}{l}\text { Antidepressant effects in FST, CS, } \\
\text { and bulbectomy }\end{array}$ & $33-35$ \\
\hline & Lamotrigine & $\begin{array}{l}\text { Inhibits voltage-dependent channels } \\
\text { to reduce glutamate release }\end{array}$ & Antidepressant effects in FST and CS & $45-47$ \\
\hline & Acamprosate & NMDA and mGluR5 antagonist & Antidepressant effects in FST & 112 \\
\hline
\end{tabular}

Note: Summary of evidence from animal models of depression and selected references are provided for drugs, grouped by class.

Abbreviations: NMDAR, N-methyl-D-aspartate receptor; CS, chronic stress; TST, tail suspension test; FST, forced swim test; LH, learned helplessness; NSFT, noveltysuppressed feeding test; GLYX-13, (S)-N-[(2S,3R)-I-amino-3-hydroxy-I-oxobutan-2-yl]-I-[(S)-I-((2S,3R)-2-amino-3-hydroxybutanoyl)pyrrolidine-2-carbonyl]pyrrolidine-2carboxamide; GluN2B, isoform of a regulatory NMDAR subunit; AMPAR, 2-amino-3-(3-hydroxy-5-methyl-isoxazol-4-yl) propanoic acid receptor; PAM, positive allosteric modulator; EMQMCM, (3-ethyl-2-methyl-quinolin-6-yl)-(4-methoxy-cyclohexyl)-methanone methanesulfonate; mGluR, metabotropic glutamate receptor; GRN-529, (4-(difluoromethoxy)-3-(pyridin-2-ylethynyl)phenyl)(5H-pyrrolo[3,4-b]pyridin-6(7H)-yl)methanone; MPEP, 2-methyl-6-(phenylethynyl)pyridine; MTEP, 3-((2-methyl-4thiazolyl)ethynyl)pyridine); LY34I495, 2-[(IS,2S)-2-carboxycyclopropyl]-3-(9H-xanthen-9-yl)-D-alanine; MGS0039, (IR,2R,3R,5R,6R)-2-amino-3-(3,4-dichlorobenzyloxy)-6fluorobicyclo[3.I.0]hexane-2,6-dicarboxylic acid; RO449I533, 4-[3-(2,6-dimethylpyridin-4-yl)phenyl]-7-methyl-8-trifluoromethyl-I,3-dihydrobenzo[b][I,4]diazepin-2-one; NAM, negative allosteric modulator; ACPT-I, (IS,3R,4S)-I-aminocyclo-pentane-I,3,4-tricarboxylic acid; LSPI-2I II, (2S)-2-amino-4-[hydroxy[hydroxy(4-hydroxy-3-methoxy5-nitro-phenyl)methyl]phosphoryl]butanoic acid; PHCCC, (-)-N-phenyl-7-(hydroxyimino)cyclopropa[b]chromen-I a-carboxamide; AMN082, N,N'-dibenzhydrylethane-I,2diamine dihydrochloride; RS-PPG, (RS)-4-phosphonophenylglycine; NMDA, N-methyl-D-aspartate.

The first report of the antidepressant effects of ketamine utilizing a controlled design in patients with MDD described a rapid onset antidepressant effect within hours following a single IV dose of $0.5 \mathrm{mg} / \mathrm{kg}$ (approximately one-fourth of the anesthetic dose). ${ }^{21}$ A second study - specifically conducted in patients with TRD - replicated the finding of a rapid antidepressant effect of ketamine compared to saline in a cross-over design and found a $70 \%$ response rate at 24 hours following a single infusion. ${ }^{22}$ Since these initial reports, several open-label studies and case reports have added to the evidence base for ketamine as a novel glutamatergic antidepressant. ${ }^{23-25}$ These findings were also extended to BPD; ketamine added to a mood stabilizer exerted a rapid antidepressant effect in BPD patients who were in a refractory depressive episode at the time of randomization. ${ }^{26,27}$

Despite the promise of an effective and mechanistically novel antidepressant, several hurdles remain before ketamine may be considered as a treatment for mood disorders outside 
Table 2 Clinical trials of glutamatergic agents in MDD

\begin{tabular}{|c|c|c|c|c|}
\hline Target & Drug & Major mechanism of action & Treatment effect & $\begin{array}{l}\text { Reference } \\
\text { numbers }\end{array}$ \\
\hline \multirow[t]{4}{*}{ NMDAR } & AZD6765 & $\begin{array}{l}\text { Low-moderate affinity } \\
\text { open-channel antagonist }\end{array}$ & $\begin{array}{l}\text { Limited evidence for antidepressant } \\
\text { efficacy to date }\end{array}$ & 66 \\
\hline & Dextromethorphan & Non-competitive antagonist & $\begin{array}{l}\text { No clinical evidence for antidepressant } \\
\text { efficacy to date }\end{array}$ & 65 \\
\hline & Ketamine & Non-competitive antagonist & Good evidence for antidepressant efficacy & $17,18,22,23$ \\
\hline & Memantine & $\begin{array}{l}\text { Non-competitive low affinity } \\
\text { antagonist }\end{array}$ & $\begin{array}{l}\text { Controlled data does not support } \\
\text { antidepressant efficacy }\end{array}$ & 117 \\
\hline NMDAR Glycine & D-cycloserine & Partial agonist at glycine site & Limited evidence for antidepressant efficacy & 69,70 \\
\hline \multirow[t]{2}{*}{ NMDAR GluN2B } & CP-I0I,606 & GluN2B selective antagonist & Preliminary evidence for antidepressant efficacy & 77 \\
\hline & MK-0657 & GluN2B selective antagonist & Preliminary evidence for antidepressant efficacy & 78 \\
\hline AMPAR & Org 26575 & PAM & $\begin{array}{l}\text { No clinical evidence for antidepressant } \\
\text { efficacy to date }\end{array}$ & 84 \\
\hline \multirow[t]{3}{*}{ Other } & Acamprosate & NMDA and mGluR5 antagonist & $\begin{array}{l}\text { Controlled data does not support } \\
\text { antidepressant efficacy }\end{array}$ & 113,114 \\
\hline & Lamotrigine & $\begin{array}{l}\text { Inhibits voltage-dependent channels } \\
\text { to reduce glutamate release }\end{array}$ & Limited evidence for antidepressant efficacy & $53-56,123-125$ \\
\hline & Riluzole & $\begin{array}{l}\text { Reduces extra-synaptic glutamate } \\
\text { by inhibiting presynaptic release, } \\
\text { enhances astroglial uptake }\end{array}$ & Preliminary evidence for antidepressant efficacy & $36-38$ \\
\hline
\end{tabular}

Note: Summary of evidence from clinical trials and selected references are provided for drugs, grouped by class.

Abbreviations: NMDAR, N-methyl-D-aspartate receptor; AZD6765, lanicemine; GluN2B, isoform of a regulatory NMDAR subunit; CP-I0I,606, Traxoprodil; D-cycloserine, Seromycin; AMPAR, 2-amino-3-(3-hydroxy-5-methyl-isoxazol-4-yl) propanoic acid receptor; PAM, positive allosteric modulator; mGluR5, metabotropic glutamate receptor 5; NMDA, N-methyl-D-aspartate; MDD, major depressive disorder

of the research setting. Regarding the question of efficacy, a degree of uncertainty remains regarding the specificity of ketamine's antidepressant effects since prior studies used only an inert placebo (ie, saline) as a control condition. A study comparing a single dose ketamine to an anesthetic control condition - the benzodiazepine anesthetic agent midazolam - in patients with TRD has recently been completed (NCT00768430) and data from this trial will provide a more rigorous assessment of ketamine's antidepressant efficacy. Additionally, therapeutic strategies designed to maintain the antidepressant effects of ketamine will need to be identified. ${ }^{28,29} \mathrm{~A}$ schedule of repeated doses of ketamine given three times a week for 2 weeks has demonstrated promise, but further controlled studies are necessary. ${ }^{24,29} \mathrm{The}$ glutamate release inhibitor riluzole (see opposite) was found to be ineffective as a relapse prevention strategy following ketamine. $^{23,28}$

Concerning safety, ketamine is a potential drug of abuse and has been associated with cognitive impairments and alterations in brain imaging measures when abused for prolonged periods of time. ${ }^{30}$ Likewise, high doses of ketamine and other NMDAR antagonists have been associated with neurotoxic effects in animal models. ${ }^{31,32}$ Interestingly, lower doses of ketamine and other NMDAR antagonists have been associated with neuroprotection and neurotrophic effects. ${ }^{33,34}$ Recently, ketamine was found to rapidly increase synaptic density and signaling in cortical neurons in conjunction with rapid antidepressant effects in animal models and to reverse stress-induced trophic deficits following chronic mild stress. ${ }^{34}$ Differences in dose and duration of exposure are likely critical variables accounting for the apparent paradoxical cellular effects of NMDARs and warrant a watchful approach to study and development of ketamine as a potential antidepressant treatment.

\section{Riluzole}

Riluzole, a glutamate modulator with neuroprotective and plasticity-enhancing properties, is FDA-approved for the treatment of amyotrophic lateral sclerosis (ALS). ${ }^{35}$ Riluzole reduces extra-synaptic glutamate by (1) inhibiting glutamate release via presynaptic inhibition of voltage-gated sodium channels, (2) enhancing astroglial uptake of glutamate, and (3) increasing AMPA receptor trafficking. ${ }^{36}$ The antidepressant effect of riluzole has been demonstrated in several animal models including forced swim test (FST), ${ }^{37}$ unpredictable stress, ${ }^{38}$ and bulbectomy models of depression. ${ }^{39}$

To date, no randomized controlled trials (RCTs) of riluzole have been published in patients with mood disorders. Following several case reports on riluzole in unipolar and bipolar depression, a 6-week, open-label monotherapy study of riluzole (mean daily dose 100-200 mg/day) in TRD found significant antidepressant effects with remission and response rates of $21 \%$ and $32 \%$ for completers, respectively. ${ }^{40}$ Another open-label study of riluzole in BPD reported changes in 
glutamate metabolites and significant improvements in depressive symptoms. ${ }^{41}$ An 8 -week augmentation trial of riluzole (50-200 mg/day) with lithium in bipolar depression reported significant improvements in depression ratings at weeks 5-8, without evidence of hypomania or mania. ${ }^{42}$ Another open-label trial of riluzole augmentation of ongoing medications in TRD demonstrated significant decreases in depression and anxiety severity that reached significance by the end of the first riluzole treatment week and persisted for the 12-week duration of the study. ${ }^{43}$ Ongoing RCTs of riluzole versus placebo augmentation of SSRI therapy in TRD will provide more definitive information regarding riluzole's potential antidepressant efficacy (NCT01204918, NCT01703039).

\section{Lamotrigine}

Lamotrigine is a glutamate release inhibitor FDA-approved for partial and tonic-clonic seizure and for BPD. Lamotrigine inhibits voltage-dependent sodium channels, calcium channels, and potassium channels; ${ }^{44}$ this is thought to decrease glutamate release and increase the AMPA receptor expression. Lamotrigine also weakly inhibits serotonin reuptake ${ }^{45}$ and may exert neuroprotective effects. ${ }^{46,47}$

Rodent studies of the antidepressant effects of lamotrigine have yielded mixed results, ${ }^{48}$ though most have reported decreased immobility time in the FST. ${ }^{49,50}$ In rats subjected to chronic unpredictable stress, chronic administration of lamotrigine ameliorated behavioral deficits in both the sucrose preference test (SPT) and novelty-suppressed feeding test (NSFT) ${ }^{51}$ In patients with BPD, lamotrigine has shown both antimanic and antidepressant properties. ${ }^{52-55}$ In contrast to the strength of data for lamotrigine in BPD, human studies of lamotrigine's efficacy in unipolar depression have been less consistent.

In TRD patients ( $\geq 2$ antidepressant failures), open-label treatment with lamotrigine resulted in significant reductions in symptoms of depression by 8 weeks and a significant improvement in social and occupational functioning at 6 months. ${ }^{56}$ Several RCTs in TRD also demonstrated efficacy. In one, comparable results were found between lamotrigine versus lithium augmentation. ${ }^{57}$ Another RCT in treatment refractory unipolar and bipolar depression found lamotrigine monotherapy to be superior to both gabapentin and placebo. ${ }^{58}$ Extending these results, Obrocea et al followed unipolar and bipolar patients, reporting improvement in both groups with a more robust effect in those with bipolar disorder. ${ }^{59}$ In contrast, several RCTs failed to show any benefit of lamotrigine on primary outcome measures. ${ }^{60-63}$ While lamotrigine is currently approved by the FDA for use in bipolar disorder, there is less support for its efficacy in unipolar depression. To date, it is unclear why divergent results have been obtained from different trials, so further studies are indicated.

\section{NMDA receptor modulators other than ketamine}

The reports of ketamine's rapid antidepressant effects coupled with preclinical reports from a variety of other agents acting at the NMDA receptor have fueled increasing interest in the development of NMDA modulators as novel therapeutics in mood disorders. ${ }^{64-66}$ Initial interest in NMDA antagonists derived from a study of a variety of NMDAR antagonists including a competitive NMDAR antagonist (2-amino-7-phosphonoheptanoic acid [AP-7]), a noncompetitive NMDAR antagonist (dizocilpine [MK-801]), and a partial agonist at the NMDAR-GLY site (1-aminocyclopropanecarboxylic acid [ACPC]), were all found to mimic the effects of clinically effective antidepressants in animal models of depression-like behavior. ${ }^{67}$

Dextromethorphan is an NMDAR antagonist initially used as a cough suppressant; more recently, the combination of dextromethorphan + quinidine (Nuedexta ${ }^{\circledR}$, Avanir Pharmaceuticals, Aliso Viejo, CA, USA) has been approved by the FDA for the treatment of pseudobulbar affect. Quinidine is a potent inhibitor of the CYP2D6 enzymatic pathway and thereby functions to raise the blood levels of dextromethorphan. In addition to NMDAR antagonism, dextromethorphan is an agonist at mu $(\mu)$ and sigma- 1 opioid receptors and blocks calcium channels, serotonin transporters, and muscarinic receptors (reviewed by Lauterbach ${ }^{68}$ ). Based on the efficacy of ketamine in depression, dextromethorphan may possess antidepressant activity, although to our knowledge, no clinical research investigating this question has been conducted to date. In the single published study, valproate augmentation with dextromethorphan versus placebo did not result in significant differences in manic or depressive symptom severity in BPD. ${ }^{69}$ Further studies are needed to determine whether dextromethorphan may provide benefit in depressive symptoms associated with MDD and BPD.

A number of novel NMDAR modulators have been developed and currently show promise as potential antidepressant agents. AZD6765 (Lanicemine, AstraZeneca, London, UK) is a low-to-moderate affinity open-channel NMDA antagonist, that has been reported in a RCT to rapidly provide short-lived relief of depressive symptoms without eliciting dissociative or psychotomimetic symptoms in a single-site clinical trial. ${ }^{70}$ This study included 22 subjects with TRD and demonstrated significant but transient differences in improvement of depressive symptom severity with AZD6765. Improvement 
was evident within 80 minutes, but significant difference from placebo only persisted until the 110-minute time point. Several other trials of AZD6765 have been completed but are not yet published and a multi-site RCT seeking to extend the period of antidepressant efficacy is currently active and recruiting patients with TRD (NCT01482221).

The NMDA receptor's glycine binding site has also been targeted for potential antidepressant drugs, partly because standard antidepressant treatments have been shown to modulate binding at this site. ${ }^{16,71} \mathrm{D}$-cycloserine (Seromycin ${ }^{\circledR}$, Eli Lilly and Co., Indianapolis, IN, USA), an antibiotic that has been used for decades to treat infections, has shown antidepressant efficacy. Initial reports suggesting possible antidepressant effects in tuberculosis patients treated with $\geq 500 \mathrm{mg} /$ day D-cycloserine included improved mood, sleep, and appetite. ${ }^{72} \mathrm{~A}$ 6-week RCT of D-cycloserine $250 \mathrm{mg}$ /day augmentation of ongoing antidepressant treatment failed to show superiority over placebo augmentation. ${ }^{73} \mathrm{In}$ contrast, a 6-week RCT of D-cycloserine $1000 \mathrm{mg} /$ day augmentation was well tolerated and elicited significant benefit over placebo ( $54 \%$ versus $15 \%$ response at endpoint) in antidepressant response. ${ }^{74}$ Newer drugs targeting the glycine site are also under investigation.

A new glycine site targeting agent, GLYX-13, is an antibody-derived tetra-peptide with partial agonist activity. ${ }^{75}$ GLYX-13 showed potential antidepressant efficacy in rats by reducing immobility on FST and ameliorated symptoms of learned helplessness. ${ }^{76} \mathrm{~A}$ Phase II trial was performed, but the results have not yet been published (NCT01234558). The company is testing other compounds in this class, and has the intention of testing these compounds in clinical trials, though no preclinical studies have yet been published or clinical trials launched. Currently a clinical RCT of low- and high-dose GLYX-13 is recruiting (NCT01684163).

The NMDAR is a tetrameric complex consisting of two NR1 and two NR2 subunits, which are available in multiple splice variants. NR2B subunit specific (GluN2B) antagonists have also shown promise as rapidly acting antidepressants. In several preclinical studies, the GluN2B antagonist Ro256981 demonstrated antidepressant efficacy by reducing immobility on the FST ${ }^{77-79}$ and increasing sucrose preference following chronic unpredictable stress (CUS).$^{80}$ These findings further motivated clinical trials of GluN2B antagonists CP-101,606 (traxoprodil), and MK-0657. In a small trial, CP-101,606 augmentation of paroxetine demonstrated antidepressant superiority over placebo with dose-related dissociative side effects. ${ }^{81}$ Although sample size may have limited statistical power, the large proportion of responders who maintained response for 1 week following a single dose, was noted. Results from a clinical trial of the orally-active compound, MK-0657, suggested potential antidepressant efficacy but the study was stopped after only five subjects were enrolled because the manufacturer discontinued compound development before the trial could be completed. ${ }^{82}$ A RCT in TRD of the NR2B antagonist EVT-101 was recently terminated though data are not yet published (NCT01128452).

\section{AMPA-targeting agents}

AMPA receptor (AMPAR) positive allosteric modulators (AMPA-PAMs; also known as AMPA potentiators or 'AMPAkines') slow the rate of AMPAR deactivation or desensitization. These agents have mainly been studied for cognitive enhancement in dementia and schizophrenia. Interest in these agents as potential antidepressants stems in part from the observation that traditional antidepressants regulate AMPARs ${ }^{83,84}$ and the ability of signaling through AMPARs to increase BDNF, ${ }^{85,86}$ in addition to glutamatergic effects. Several AMPAR potentiators have also shown promise in preclinical studies of mood disorders. To our knowledge, the only published placebo-controlled clinical trials of an AMPA-PAM in mood disorder patients involve Org $26575 .{ }^{87,88}$ A Phase II study of Org 26575 failed to show a significant separation from placebo, although efficacy was not the primary endpoint of this study. ${ }^{88}$ The study did demonstrate tolerability, suggesting that further, well-powered studies are indicated to assess efficacy of this agent. Another agent from this class, the AMPAR potentiator Org 24448, was previously studied in major depression, but the RCT was discontinued (Clinicaltrials.gov identifier: NCT00113022). In this context, the tolerability demonstrated for Org 26575 is important for motivating further studies of AMPA acting agents.

LY392098 and LY451646 - biarylsulphonamide AMPAR potentiators - reduced immobility in the forced swim and tail suspension tests (FST, TST), and LY392098's effects were blocked by an AMPAR antagonist. ${ }^{89,90}$ Bidirectional antidepressant synergism was also reported between LY392098 and traditional antidepressants on FST. ${ }^{91}$ In a less common model of depression, two benzoylpyrrolidinones (aniracetam and piracetam) and three benzoylpyrrolidines (Ampakines; CX516, CX691, and CX731) all reduced submissive behavior regarding a rewarding food source. ${ }^{92}$ In this study, more rapid and greater action was reported for these compounds than fluoxetine. Aniracetam has also been found to reduce immobility time on FST in aged but not young rats. ${ }^{93}$ The preclinical promise of these AMPA specific agents warrants further exploration in controlled clinical trials. 


\section{Metabotropic glutamate receptor-targeting agents}

G-protein coupled metabotropic glutamate receptors (mGluRs) exert modulatory effects on neuronal function through signal transduction and have shown promise for the treatment of depression and anxiety in preclinical studies. Notably, Group I mGluRs (mGluR1, mGluR5) are functionally coupled to NMDARs and may regulate NMDAR-stimulated synaptic plasticity among other cellular functions. ${ }^{94,95}$ mGluR5 antagonists MPEP and MTEP have been repeatedly found to reduce immobility on TST and FST, independently and synergistically with imipramine. ${ }^{96-98}$ Antidepressant-like effects of MTEP on FST were found to depend on NMDAR but not on AMPAR signaling. ${ }^{99}$ Similarly, the mGluR5 negative allosteric modulator (NAM) GRN-529 results in antidepressant-like effects, reducing immobility time on FST. ${ }^{100}$ Results have not been published from two RCTs of mGluR5 negative modulators in MDD, RO4917523 (NCT00809562) and AZD2066 (NCT1145755). However, a follow-up study of RO4917523 versus placebo augmentation in MDD is currently recruiting (NCT1437657). The mGluR1 antagonist EMQMCM also decreased immobility on TST and FST. ${ }^{101}$ Other approved treatments synergized the FST effects of MTEP and EMQMCM. ${ }^{102}$

Selective antagonists of group II mGluR2/3, LY341495 and MGS0039 and the NAM group II modulator RO4491533 variably reduced depressive-like behavior on TST, FST, and foot shock-related learned helplessness, and these effects were found to be AMPAR-dependent. ${ }^{103-107}$ LY341495 also reduced nicotine withdrawal-related anhedonia as assessed by intracranial self-stimulation. ${ }^{108}$ An ongoing RCT of RO4995819 in major depression (NCT1457677) will provide human data for antidepressant efficacy of a related mGluR2/3 negative allosteric modulator.

The group III mGluR agonist, ACPT-I and the mGluR8 specific agonist (RS)-4-phosphonophenylglycine (RS-PPG), showed antidepressant-like effects on FST, which were reversed through mGluR group III antagonism, ${ }^{109,110}$ though effects on FST and TST were not replicated when ACPT-1 was peripherally administered. ${ }^{111}$ Moreover, the effect of ACPT-1 was facilitated by a positive allosteric modulator of mGluR4, (-)-N-phenyl-7-(hydroxyimino) cyclopropa[b]chromen-1a-carboxamide (PHCCC). ${ }^{12}$ However, when administered alone, the mGluR4 positive allosteric modulators, Lu AF21934 and LSP1-2111, failed to exhibit antidepressant-like activity on TST and FST. ${ }^{113,114}$ The mGluR7 selective agonist, $\mathrm{N}, \mathrm{N}^{\prime}$-dibenzyhydryl-ethane1,2-diamine dihydrochloride (AMN082), also was reported to decrease immobility on FST and TST, and similar effects were not seen in animals lacking mGluR7, though high doses impaired locomotor activity. ${ }^{115}$

\section{Conclusion}

The limited efficacy and delayed onset of action of standard monoaminergic antidepressants compels the search for new therapeutics with novel mechanisms of action. A growing body of evidence implicates dysregulation of the glutamate system as a key pathophysiological feature of mood disorders, thereby making the glutamate system a prime target for innovative treatments. The data reviewed herein suggest that agents directly targeting glutamatergic transmission show promise for expanding the scope and efficacy of antidepressant treatments. Ketamine in particular offers a proof of principal for modulation of the NMDAR as a novel antidepressant strategy. In the future, ketamine may provide a hospital-based treatment option for patients with refractory forms of depression or in cases where rapid treatment is required, for example, in the case of acute suicidal ideation. Much more research investigating the longer-term safety and efficacy of ketamine, however, is necessary before this can be recommended as a treatment. While lamotrigine is currently approved by the FDA for use in BPD, its efficacy in unipolar depression or TRD is less compelling. Riluzole possesses limited evidence for efficacy in unipolar and bipolar depression but larger definitive studies are required before widespread clinical use can be recommended.

Additional glutamatergic agents marketed for non-mood disorder conditions are under consideration as potential antidepressant agents. For example, acamprosate, used for the treatment of alcohol abuse, which also has antagonist activity at both NMDAR and mGluR5 receptors, has shown antidepressant-like activity on the TST ${ }^{116}$ along with trends but not statistically significant improvements in underpowered studies of depressive symptoms in patients with comorbid depression and alcohol dependence. ${ }^{117,118}$ However, another NMDA modulator - memantine - has not demonstrated efficacy in depression. Memantine (Namenda) is an amantadine derivative and voltage-dependent noncompetitive low-affinity NMDAR antagonist, and is approved for the treatment of moderate-to-severe Alzheimer's disease. ${ }^{119}$ While memantine demonstrated antidepressant effects in multiple animal models of depression including FST and chronic mild stress, ${ }^{120}$ results from RCTs of memantine in human depression have failed to demonstrate antidepressant benefit. ${ }^{121}$ Memantine's low-affinity and fast off-rate have been suggested as possible explanations for 
the lack of antidepressant efficacy. ${ }^{122}$ Substantially more research is required on these compounds before they can be recommended for clinical use in mood disorders.

Innovative experimental agents with significant therapeutic promise in mood disorders based on preclinical data include novel NMDAR modulators (including NR2B subtype-selective agents), AMPA-PAMs, and selective mGluR PAMs and NAMs. Additional components of the glutamate regulatory machinery may be suitable for future drug development, including EAATs. Glutamate uptake by EAATs is the primary means by which glutamate is removed from the extracellular space, thereby limiting the potential for excitotoxicity caused by excessive glutamate signaling. Compounds capable of increasing the activity of EAATs may have antidepressant properties and a series of small molecules that may enhance EAAT levels have recently been described. ${ }^{123}$ Future preclinical studies will be needed to test the hypothesized antidepressant effect of these agents.

Taken together, both preclinical and clinical evidence exists to support the pursuit of small molecule modulators of the glutamate system as novel therapeutic agents in mood disorders. This effort represents a critical departure from reliance on developing compounds that target the monoamine system, yielding so called 'me too' drugs which do not typically differ in clinically meaningful ways from previously marketed antidepressants. It is hoped that by targeting neural systems outside of the monoamine system, more effective and perhaps faster acting therapeutics can be developed for patients suffering from these disabling disorders.

\section{Acknowledgment/disclosure}

Dr Murrough is supported by a Career Development Award from NIH/NIMH (K23MH094707) and by the American Foundation for Suicide Prevention (AFSP). Dr Murrough receives research support from Janssen Research and Development and Avanir Pharmaceuticals. Dr Lapidus has received grant support from NARSAD/Brain and Behavior Research Foundation, Simons Foundation, and APIRE/ Janssen Psychiatric Research Scholars Program. He has received a fee for interview with LCN Consulting, Inc. Dr Soleimani reports no disclosures. Institutional conflict: Dr Charney, Dean of Mount Sinai School of Medicine, has been named as an inventor on a use-patent of ketamine for the treatment of depression. If ketamine were shown to be effective in the treatment of depression and received approval from the US Food and Drug Administration for this indication, Dr Charney and Mount Sinai School of Medicine could benefit financially.

\section{References}

1. Collins PY, Patel V, Joestl SS, et al. Grand challenges in global mental health. Nature. 2011;475(7354):27-30.

2. Trivedi MH, Rush AJ, Wisniewski SR, et al; STAR*D Study Team. Evaluation of outcomes with citalopram for depression using measurement-based care in STAR*D: implications for clinical practice. Am J Psychiatry. 2006;163(1):28-40.

3. Fava M, Davidson KG. Definition and epidemiology of treatmentresistant depression. Psychiatr Clin North Am. 1996;19(2):179-200.

4. Rush AJ, Wisniewski SR, Zisook S, et al. Is prior course of illness relevant to acute or longer-term outcomes in depressed out-patients? A STAR*D report. Psychol Med. 2012;42(6):1131-1149.

5. Rush AJ, Trivedi MH, Wisniewski SR, et al. Acute and longer-term outcomes in depressed outpatients requiring one or several treatment steps: a STAR*D report. Am J Psychiatry. 2006;163(11):1905-1917.

6. Judd LL, Akiskal HS, Schettler PJ, et al. A prospective investigation of the natural history of the long-term weekly symptomatic status of bipolar II disorder. Arch Gen Psychiatry. 2003;60(3):261-269.

7. Nierenberg AA, Ostacher MJ, Calabrese JR, et al. Treatment-resistant bipolar depression: a STEP-BD equipoise randomized effectiveness trial of antidepressant augmentation with lamotrigine, inositol, or risperidone. Am J Psychiatry. 2006;163(2):210-216.

8. Krishnan V, Nestler EJ. Linking molecules to mood: new insight into the biology of depression. Am J Psychiatry. 2010;167(11):1305-1320.

9. Miller G. Is pharma running out of brainy ideas? Science. 2010;329(5991): 502-504.

10. Orrego F, Villanueva S. The chemical nature of the main central excitatory transmitter: a critical appraisal based upon release studies and synaptic vesicle localization. Neuroscience. 1993;56(3):539-555.

11. Hashimoto K, Sawa A, Iyo M. Increased levels of glutamate in brains from patients with mood disorders. Biol Psychiatry. 2007;62(11): 1310-1316.

12. Auer DP, Pütz B, Kraft E, Lipinski B, Schill J, Holsboer F. Reduced glutamate in the anterior cingulate cortex in depression: an in vivo proton magnetic resonance spectroscopy study. Biol Psychiatry. 2000;47(4): 305-313.

13. Sanacora G, Gueorguieva R, Epperson CN, et al. Subtype-specific alterations of gamma-aminobutyric acid and glutamate in patients with major depression. Arch Gen Psychiatry. 2004;61(7): 705-713.

14. Hashimoto K. Emerging role of glutamate in the pathophysiology of major depressive disorder. Brain Res Rev. 2009;61(2):105-123.

15. Beneyto M, Kristiansen LV, Oni-Orisan A, McCullumsmith RE, Meador-Woodruff JH. Abnormal glutamate receptor expression in the medial temporal lobe in schizophrenia and mood disorders. Neuropsychopharmacology. 2007;32(9):1888-1902.

16. Paul IA, Nowak G, Layer RT, Popik P, Skolnick P. Adaptation of the $\mathrm{N}$-methyl-D-aspartate receptor complex following chronic antidepressant treatments. J Pharmacol Exp Ther. 1994;269(1):95-102.

17. Mathews DC, Henter ID, Zarate CA. Targeting the glutamatergic system to treat major depressive disorder: rationale and progress to date. Drugs. 2012;72(10):1313-1333.

18. Musazzi L, Treccani G, Mallei A, Popoli M. The action of antidepressants on the glutamate system: regulation of glutamate release and glutamate receptors. Biol Psychiatry. 2013;73(12):1180-1188.

19. Serafini G, Pompili M, Innamorati M, Dwivedi Y, Brahmachari G, Girardi P. Pharmacological properties of glutamatergic drugs targeting NMDA receptors and their application in major depression. Curr Pharm Des. 2013;19(10):1898-1922.

20. Green SM, Johnson NE. Ketamine sedation for pediatric procedures: Part 2, Review and implications. Ann Emerg Med. 1990;19(9): 1033-1046.

21. Berman RM, Cappiello A, Anand A, et al. Antidepressant effects of ketamine in depressed patients. Biol Psychiatry. 2000;47(4):351-354.

22. Zarate CA Jr, Singh JB, Carlson PJ, et al. A randomized trial of an N-methyl-D-aspartate antagonist in treatment-resistant major depression. Arch Gen Psychiatry. 2006;63(8):856-864. 
23. Mathew SJ, Murrough JW, aan het Rot M, Collins KA, Reich DL, Charney DS. Riluzole for relapse prevention following intravenous ketamine in treatment-resistant depression: a pilot randomized, placebocontrolled continuation trial. Int J Neuropsychopharmacol. 2010;13(1): $71-82$.

24. aan het Rot M, Collins KA, Murrough JW, et al. Safety and efficacy of repeated-dose intravenous ketamine for treatment-resistant depression. Biol Psychiatry. 2010;67(2):139-145.

25. Murrough JW, Perez AM, Mathew SJ, Charney DS. A case of sustained remission following an acute course of ketamine in treatment-resistant depression. J Clin Psychiatry. 2011;72(3):414-415.

26. Diazgranados N, Ibrahim L, Brutsche NE, et al. A randomized add-on trial of an N-methyl-D-aspartate antagonist in treatment-resistant bipolar depression. Arch Gen Psychiatry. 2010;67(8):793-802.

27. Zarate CA Jr, Brutsche NE, Ibrahim L, et al. Replication of ketamine's antidepressant efficacy in bipolar depression: a randomized controlled add-on trial. Biol Psychiatry. 2012;71(11):939-946.

28. Ibrahim L, Diazgranados N, Franco-Chaves J. Course of improvement in depressive symptoms to a single intravenous infusion of ketamine vs add-on riluzole: results from a 4-week, double-blind, placebo-controlled study. Neuropsychopharmacology. 2012;37(6):1526-1533.

29. Murrough JW, Perez AM, Pillemer S, et al. Rapid and longer-term antidepressant effects of repeated ketamine infusions in treatmentresistant major depression. Biol Psychiatry. Epub July 26, 2012.

30. Morgan CJ, Muetzelfeldt L, Curran HV. Ketamine use, cognition and psychological wellbeing: a comparison of frequent, infrequent and exusers with polydrug and non-using controls. Addiction. 2009;104(1): $77-87$.

31. Olney JW, Labruyere J, Wang G, Wozniak DF, Price MT, Sesma MA. NMDA antagonist neurotoxicity: mechanism and prevention. Science. 1991;254(5037):1515-1518.

32. Olney JW, Labruyere J, Price MT. Pathological changes induced in cerebrocortical neurons by phencyclidine and related drugs. Science. 1989;244(4910):1360-1362.

33. Manji HK, Quiroz JA, Sporn J, et al. Enhancing neuronal plasticity and cellular resilience to develop novel, improved therapeutics for difficult-to-treat depression. Biol Psychiatry. 2003;53(8):707-742.

34. Duman RS, Aghajanian GK. Synaptic dysfunction in depression: potential therapeutic targets. Science. 2012;338(6103):68-72.

35. Bensimon G, Lacomblez L, Meininger V. A controlled trial of riluzole in amyotrophic lateral sclerosis. ALS/Riluzole Study Group. $N$ Engl $J$ Med. 1994;330(9):585-591.

36. Zarate CA, Manji HK. Riluzole in psychiatry: a systematic review of the literature. Expert Opin Drug Metab Toxicol. 2008;4(9):1223-1234.

37. Gourley SL, Espitia JW, Sanacora G, Taylor JR. Antidepressant-like properties of oral riluzole and utility of incentive disengagement models of depression in mice. Psychopharmacology (Berl). 2012;219(3): 805-814.

38. Banasr M, Chowdhury GM, Terwilliger R, et al. Glial pathology in an animal model of depression: reversal of stress-induced cellular, metabolic and behavioral deficits by the glutamate-modulating drug riluzole. Mol Psychiatry. 2010;15(5):501-511.

39. Takahashi K, Murasawa $\mathrm{H}$, Yamaguchi $\mathrm{K}$, et al. Riluzole rapidly attenuates hyperemotional responses in olfactory bulbectomized rats, an animal model of depression. Behav Brain Res. 2011;216(1):46-52.

40. Zarate CA Jr, Payne JL, Quiroz J, et al. An open-label trial of riluzole in patients with treatment-resistant major depression. Am J Psychiatry. 2004;161(1):171-174.

41. Brennan BP, Hudson JI, Jensen JE, et al. Rapid enhancement of glutamatergic neurotransmission in bipolar depression following treatment with riluzole. Neuropsychopharmacology. 2010;35(3):834-846.

42. Zarate CA Jr, Quiroz JA, Singh JB, et al. An open-label trial of the glutamate-modulating agent riluzole in combination with lithium for the treatment of bipolar depression. Biol Psychiatry. 2005;57(4):430-432.

43. Sanacora G, Kendell SF, Levin Y, et al. Preliminary evidence of riluzole efficacy in antidepressant-treated patients with residual depressive symptoms. Biol Psychiatry. 2007;61(6):822-882.
44. Grunze H, von Wegerer J, Greene RW, Walden J. Modulation of calcium and potassium currents by lamotrigine. Neuropsychobiology. 1998;38(3):131-138.

45. Southam E, Kirkby D, Higgins GA, Hagan RM. Lamotrigine inhibits monoamine uptake in vitro and modulates 5-hydroxytryptamine uptake in rats. Eur J Pharmacol. 1998;358(1):19-24.

46. Crumrine RC, Bergstrand K, Cooper AT, Faison WL, Cooper BR. Lamotrigine protects hippocampal CA1 neurons from ischemic damage after cardiac arrest. Stroke. 1997;28(11):2230-2236; discussion 2237.

47. Maj R, Fariello RG, Ukmar G, et al. PNU-151774E protects against kainate-induced status epilepticus and hippocampal lesions in the rat. Eur J Pharmacol. 1998;359(1):27-32.

48. Szymczyk G, Zebrowska-Lupina I. Influence of antiepileptics on efficacy of antidepressant drugs in forced swimming test. Pol $J$ Pharmacol. 2000;52(5):337-344.

49. Bourin M, Masse F, Hascoët M. Evidence for the activity of lamotrigine at 5-HT(1A) receptors in the mouse forced swimming test. $J$ Psychiatry Neurosci. 2005;30(4):275-282.

50. Consoni FT, Vital MA, Andreatini R. Dual monoamine modulation for the antidepressant-like effect of lamotrigine in the modified forced swimming test. Eur Neuropsychopharmacol. 2006;16(6):451-458.

51. Li N, He X, Zhang Y, et al. Brain-derived neurotrophic factor signalling mediates antidepressant effects of lamotrigine. Int $J$ Neuropsychopharmacol. 2011;14(8):1091-1098.

52. Goodwin GM, Bowden CL, Calabrese JR, et al. A pooled analysis of 2 placebo-controlled 18-month trials of lamotrigine and lithium maintenance in bipolar I disorder. J Clin Psychiatry. 2004;65(3):432-441.

53. Bowden CL, et al. A placebo-controlled 18-month trial of lamotrigine and lithium maintenance treatment in recently manic or hypomanic patients with bipolar I disorder. Arch Gen Psychiatry. 2003;60(4): 392-400.

54. Calabrese JR, Bowden CL, Sachs G, et al; Lamictal 605 Study Group. A placebo-controlled 18-month trial of lamotrigine and lithium maintenance treatment in recently depressed patients with bipolar I disorder. J Clin Psychiatry. 2003;64(9):1013-1024.

55. Calabrese JR, Suppes T, Bowden CL, et al. A double-blind, placebocontrolled, prophylaxis study of lamotrigine in rapid-cycling bipolar disorder. Lamictal 614 Study Group. J Clin Psychiatry. 2000;61(11): 841-850.

56. Gabriel A. Lamotrigine adjunctive treatment in resistant unipolar depression: an open, descriptive study. Depress Anxiety. 2006;23(8): 485-488.

57. Schindler F, Anghelescu IG. Lithium versus lamotrigine augmentation in treatment resistant unipolar depression: a randomized, open-label study. Int Clin Psychopharmacol. 2007;22(3):179-182.

58. Frye MA, Ketter TA, Kimbrell TA, et al. A placebo-controlled study of lamotrigine and gabapentin monotherapy in refractory mood disorders. J Clin Psychopharmacol. 2000;20(6):607-614.

59. Obrocea GV, Dunn RM, Frye MA, et al. Clinical predictors of response to lamotrigine and gabapentin monotherapy in refractory affective disorders. Biol Psychiatry. 2002;51(3):253-260.

60. Santos MA, Rocha FL, Hara C. Efficacy and safety of antidepressant augmentation with lamotrigine in patients with treatment-resistant depression: a randomized, placebo-controlled, double-blind study. Prim Care Companion J Clin Psychiatry. 2008;10(3):187-190.

61. Barbosa L, Berk M, Vorster M. A double-blind, randomized, placebocontrolled trial of augmentation with lamotrigine or placebo in patients concomitantly treated with fluoxetine for resistant major depressive episodes. J Clin Psychiatry. 2003;64(4):403-407.

62. Normann C, Hummel B, Schärer LO, Hörn M, Grunze H, Walden J. Lamotrigine as adjunct to paroxetine in acute depression: a placebocontrolled, double-blind study. J Clin Psychiatry. 2002;63(4):337-344.

63. Barbee JG, Thompson TR, Jamhour NJ, et al. A double-blind placebocontrolled trial of lamotrigine as an antidepressant augmentation agent in treatment-refractory unipolar depression. J Clin Psychiatry. 2011;72(10):1405-1012. 
64. Krystal JH, Sanacora G, Blumberg H, et al. Glutamate and GABA systems as targets for novel antidepressant and mood-stabilizing treatments. Mol Psychiatry. 2002;7 Suppl 1:S71-S80.

65. Murrough JW, Charney DS. Cracking the moody brain: lifting the mood with ketamine. Nat Med. 2010;16(12):1384-1385.

66. Murrough JW, Charney DS. Is there anything really novel on the antidepressant horizon? Curr Psychiatry Rep. 2012;14(6):643-649.

67. Trullas R, Skolnick P. Functional antagonists at the NMDA receptor complex exhibit antidepressant actions. Eur Pharmacol. 1990;185(1): $1-10$.

68. Lauterbach EC. Dextromethorphan as a potential rapid-acting antidepressant. Med Hypotheses. 2011;76(5):717-719.

69. Lee SY, Chen SL, Chang YH, et al. The DRD2/ANKK1 gene is associated with response to add-on dextromethorphan treatment in bipolar disorder. J Affect Disord. 2012;138(3):295-300.

70. Zarate CA Jr, Mathews D, Ibrahim L, et al. A randomized trial of a low-trapping nonselective N-methyl-D-aspartate channel blocker in major depression. Biol Psychiatry. Epub November 30, 2012.

71. Popik P, Wróbel M, Nowak G. Chronic treatment with antidepressants affects glycine/NMDA receptor function: behavioral evidence. Neuropharmacology. 2000;39(12):2278-2287.

72. Crane GE. Cyloserine as an antidepressant agent. Am J Psychiatry. 1959;115(11):1025-1026.

73. Heresco-Levy U, Javitt DC, Gelfin Y, et al. Controlled trial of D-cycloserine adjuvant therapy for treatment-resistant major depressive disorder. J Affect Disorder. 2006;93(1-3):239-243.

74. Heresco-Levy U, Gelfin G, Bloch B, et al. A randomized add-on trial of high-dose d-cycloserine for treatment-resistant depression. Int $J$ Neuropsychopharmacol. 2013;16(3):501-506.

75. Moskal JR, Kuo AG, Weiss C, et al. GLYX-13: a monoclonal antibody-derived peptide that acts as an N-methyl-D-aspartate receptor modulator. Neuropharmacology. 2005;49(7):1077-1087.

76. Burgdorf J, Zhang XL, Nicholson KL, et al. GLYX-13, a NMDA receptor glycine-site functional partial agonist, induces antidepressant-like effects without ketamine-like side effects. Neuropsychopharmacology. 2013;38(5):729-742

77. Maeng S, Zarate CA Jr, Du J, et al. Cellular mechanisms underlying the antidepressant effects of ketamine: role of alpha-amino-3-hydroxy-5methylisoxazole-4-propionic acid receptors. Biol Psychiatry. 2008;63(4): 349-552.

78. Li N, Lee B, Liu RJ, et al. mTOR-dependent synapse formation underlies the rapid antidepressant effects of NMDA antagonists. Science. 2010;329(5994):959-964.

79. Zhang L, Xu T, Wang S, et al. NMDA GluN2B receptors involved in the antidepressant effects of curcumin in the forced swim test. Prog Neuropsychopharmacol Biol Psychiatry. 2013;40:12-17.

80. Li N, Liu RJ, Dwyer JM, et al. Glutamate N-methyl-D-aspartate receptor antagonists rapidly reverse behavioral and synaptic deficits caused by chronic stress exposure. Biol Psychiatry. 2011;69(8):754-761.

81. Preskorn SH, Baker B, Kolluri S, Menniti FS, Krams M, Landen JW. An innovative design to establish proof of concept of the antidepressant effects of the NR2B subunit selective N-methyl-D-aspartate antagonist, CP-101,606, in patients with treatment-refractory major depressive disorder. J Clin Psychopharmacol. 2008;28(6):631-637.

82. Ibrahim L, Diaz Granados N, Jolkovsky L, et al. A randomized, placebocontrolled, crossover pilot trial of the oral selective NR2B antagonist MK-0657 in patients with treatment-resistant major depressive disorder. J Clin Psychopharmacol. 2012;32(4):551-557.

83. Bobula B, Hess G. Antidepressant treatments-induced modifications of glutamatergic transmission in rat frontal cortex. Pharmacol Rep. 2008;60(6):865-871

84. Pittaluga A, Raiteri L, Longordo F, et al. Antidepressant treatments and function of glutamate ionotropic receptors mediating amine release in hippocampus. Neuropharmacology. 2007;53(1):27-36.

85. Hayashi T, Umemori H, Mishina M, Yamamoto T. The AMPA receptor interacts with and signals through the protein tyrosine kinase Lyn. Nature. 1999;397(6714):72-77.
86. Mackowiak M, O’Neill MJ, Hicks CA, Bleakman D, Skolnick P. An AMPA receptor potentiator modulates hippocampal expression of BDNF: an in vivo study. Neuropharmacology. 2002;43(1): $1-10$.

87. Nations KR, Bursi R, Dogterom P, et al. Maximum tolerated dose evaluation of the AMPA modulator Org 26576 in healthy volunteers and depressed patients: a summary and method analysis of bridging research in support of phase II dose selection. Drugs R D. 2012;12(3): 127-139.

88. Nations KR, Dogterom P, Bursi R, et al. Examination of Org 26576, an AMPA receptor positive allosteric modulator, in patients diagnosed with major depressive disorder: an exploratory, randomized, doubleblind, placebo-controlled trial. J Psychopharmacol. 2012;26(12): 1525-1539.

89. Li X, Tizzano JP, Griffey K, Clay M, Lindstrom T, Skolnick P. Antidepressant-like actions of an AMPA receptor potentiator (LY392098). Neuropharmacology. 2001;40(8):1028-1033.

90. Bai F, Li X, Clay M, Lindstrom T, Skolnick P. Intra- and interstrain differences in models of 'behavioral despair'. Pharmacol Biochem Behav. 2001;70(2-3):187-192.

91. Li X, Witkin JM, Need AB, Skolnick P. Enhancement of antidepressant potency by a potentiator of AMPA receptors. Cell Mol Neurobiol. 2003;23(3):419-430.

92. Knapp RJ, Goldenberg R, Shuck C, et al. Antidepressant activity of memory-enhancing drugs in the reduction of submissive behavior model. Eur J Pharmacol. 2002;440(1):27-35.

93. Nakamura K, Tanaka Y. Antidepressant-like effects of aniracetam in aged rats and its mode of action. Psychopharmacology. 2001;158(2): 205-212.

94. Mannaioni G, Marino MJ, Valenti O, Traynelis SF, Conn PJ. Metabotropic glutamate receptors 1 and 5 differentially regulate CA1 pyramidal cell function. J Neurosci. 2001;21(16):5925-5934.

95. Ayala JE, Chen Y, Banko JL, et al. mGluR5 positive allosteric modulators facilitate both hippocampal LTP and LTD and enhance spatial learning. Neuropsychopharmacology. 2009;34(9):2057-2071.

96. Tatarczyńska E, Klodzińska A, Chojnacka-Wójcik E, et al. Potential anxiolytic- and antidepressant-like effects of MPEP, a potent, selective and systemically active mGlu5 receptor antagonist. British J Pharmacol. 2001;132(7):1423-1430.

97. Pałucha A, Brański P, Szewczyk B, Wierońska JM, Kłak K, Pilc A. Potential antidepressant-like effect of MTEP, a potent and highly selective mGluR5 antagonist. Pharmacol Biochem Behav. 2005;81(4): 901-906.

98. Li X, Need AB, Baez M, Witkin JM. Metabotropic glutamate 5 receptor antagonism is associated with antidepressant-like effects in mice. J Pharmacol Exp Ther. 2006;319(1):254-259.

99. Pomierny-Chamioło L, Poleszak E, Pilc A, Nowak G. NMDA but not AMPA glutamatergic receptors are involved in the antidepressant-like activity of MTEP during the forced swim test in mice. Pharmacol Rep 2010;62(6):1186-1190.

100. Hughes ZA, Neal SJ, Smith DL, et al. Negative allosteric modulation of metabotropic glutamate receptor 5 results in broad spectrum activity relevant to treatment resistant depression. Neuropharmacology. 2013;66:202-214.

101. Belozertseva IV, Kos T, Popik P, Danysz W, Bespalov AY. Antidepressant-like effects of mGluR1 and mGluR5 antagonists in the rat forced swim and the mouse tail suspension tests. European Neuropsychopharmacol. 2007;17(3):172-179.

102. Molina-Hernández M, Tellez-Alcántara NP, Pérez-García J, Olivera-Lopez JI, Jaramillo-Jaimes MT. Antidepressant-like actions of minocycline combined with several glutamate antagonists. Prog Neuropsychopharmacol Biol Psychiatry. 2008;32(2): 380-386.

103. Yoshimizu T, Shimazaki T, Ito A, Chaki S. An mGluR2/3 antagonist, MGS0039, exerts antidepressant and anxiolytic effects in behavioral models in rats. Psychopharmacology. 2006;186(4): 587-593. 
104. Karasawa J, Shimazaki T, Kawashima N, Chaki S. AMPA receptor stimulation mediates the antidepressant-like effect of a group II metabotropic glutamate receptor antagonist. Brain Res. 2005;1042(1): 92-98.

105. Chaki S, Yoshikawa R, Hirota S, et al. MGS0039: a potent and selective group II metabotropic glutamate receptor antagonist with antidepressant-like activity. Neuropharmacology. 2004;46(4): 457-467.

106. Bespalov AY, van Gaalen MM, Sukhotina IA, et al. Behavioral characterization of the mGlu group II/III receptor antagonist, LY-341495, in animal models of anxiety and depression. Eur $J$ Pharmacol. 2008;592(1-3):96-102.

107. Campo B, Kalinichev M, Lambeng N, et al. Characterization of an mGluR2/3 negative allosteric modulator in rodent models of depression. J Neurogenet. 2011;25(4):152-166.

108. Kenny PJ, Gasparini F, Markou A. Group II metabotropic and alphaamino-3-hydroxy-5-methyl-4-isoxazole propionate (AMPA)/kainate glutamate receptors regulate the deficit in brain reward function associated with nicotine withdrawal in rats. J Pharmacol Exp Ther. 2003;306(3):1068-1076.

109. Tatarczyńska E, Pałucha A, Szewczyk B, Chojnacka-Wójcik E, Wierońska J, Pilc A. Anxiolytic- and antidepressant-like effects of group III metabotropic glutamate agonist (1S,3R,4S)-1aminocyclopentane-1,3,4-tricarboxylic acid (ACPT-I) in rats. Pol J Pharmacol. 2002;54(6):707-710.

110. Pałucha A, Tatarczyńska E, Brański P, et al. Group III mGlu receptor agonists produce anxiolytic- and antidepressant-like effects after central administration in rats. Neuropharmacology. 2004;46(2):151-159.

111. Stachowicz K, Kłodzińska A, Palucha-Poniewiera A, Schann S, Neuville P, Pilc A. The group III mGlu receptor agonist ACPT-I exerts anxiolytic-like but not antidepressant-like effects, mediated by the serotonergic and GABA-ergic systems. Neuropharmacology. 2009;57(3):227-234

112. Kłak K, Pałucha A, Brański P, Sowa M, Pilc A. Combined administration of PHCCC, a positive allosteric modulator of $\mathrm{mGlu} 4$ receptors and ACPT-I, mGlu III receptor agonist evokes antidepressant-like effects in rats. Amino acids. 2007;32(2):169-172.

113. Sławińska A, Wierońska JM, Stachowicz K, et al. Anxiolytic- but not antidepressant-like activity of Lu AF21934, a novel, selective positive allosteric modulator of the $\mathrm{mGlu}(4)$ receptor. Neuropharmacology. $2013 ; 66: 225-235$
114. Wierońska JM, Stachowicz K, Pałucha-Poniewiera A, Acher F, Brański P, Pilc A. Metabotropic glutamate receptor 4 novel agonist LSP1-2111 with anxiolytic, but not antidepressant-like activity, mediated by serotonergic and GABAergic systems. Neuropharmacology. 2010; 59(7-8):627-634.

115. Palucha A, Klak K, Branski P, van der Putten H, Flor PJ, Pilc A. Activation of the $\mathrm{mGlu} 7$ receptor elicits antidepressant-like effects in mice. Psychopharmacology. 2007;194(4):555-562.

116. Pałucha-Poniewiera A, Pilc A. Involvement of mGlu5 and NMDA receptors in the antidepressant-like effect of acamprosate in the tail suspension test. Prog Neuropsychopharmacol Biol Psychiatry. 2012;39(1):102-106.

117. Tolliver BK, Desantis SM, Brown DG, Prisciandaro JJ, Brady KT. A randomized, double-blind, placebo-controlled clinical trial of acamprosate in alcohol-dependent individuals with bipolar disorder: a preliminary report. Bipolar Disord. 2012;14(1):54-63.

118. Witte J, Bentley K, Evins AE, et al. A randomized, controlled, pilot study of acamprosate added to escitalopram in adults with major depressive disorder and alcohol use disorder. J Clin Psychopharmacol. 2012;32(6):787-796.

119. Langa KM, Foster NL, Larson EB. Mixed dementia: emerging concepts and therapeutic implications. JAMA. 2004;292(23):2901-2908.

120. Quan MN, Zhang N, Wang YY, Zhang T, Yang Z. Possible antidepressant effects and mechanisms of memantine in behaviors and synaptic plasticity of a depression rat model. Neuroscience. 2011;182: 88-97.

121. Zarate CA Jr, Singh JB, Quiroz JA, et al. A double-blind, placebocontrolled study of memantine in the treatment of major depression. Am J Psychiatry. 2006;163(1):153-155.

122. Tsai GE. Searching for rational anti N-methyl-D-aspartate treatment for depression. Arch Gen Psychiatry. 2007;64(9):1099-1100; author reply $1100-1101$.

123. Colton CK, Kong Q, Lai L, et al. Identification of translational activators of glial glutamate transporter EAAT2 through cell-based high-throughput screening: an approach to prevent excitotoxicity. J Biomol Screen. 2010;15(6):653-662.
Neuropsychiatric Disease and Treatment

\section{Publish your work in this journal}

Neuropsychiatric Disease and Treatment is an international, peerreviewed journal of clinical therapeutics and pharmacology focusing on concise rapid reporting of clinical or pre-clinical studies on a range of neuropsychiatric and neurological disorders. This journal is indexed on PubMed Central, the 'PsycINFO' database and CAS.
Dovepress

The manuscript management system is completely online and includes a very quick and fair peer-review system, which is all easy to use. Visit http://www.dovepress.com/testimonials.php to read real quotes from published authors. 